senior decision-making skills which may reflect service provision demands. This emphasises the need for further interventions and trainee support to facilitate this transition both at a local and national level.

\section{G377 BALINT GROUP IN THE NEONATAL UNIT: AN OPPORTUNITY FOR ENGAGED REFLECTION}

K Burke, S Fitch. Cardiff and Vale UHB, University Hospital Wales, Cardiff, UK

\subsection{6/archdischild-2020-rcpch.322}

Background The NICU is recognised as an area of especially potent moral distress and compassion fatigue. Balint Groups are named after the psychoanalysts Michael and Enid Balint, who began work in the 1950s to help General Practitioners reach a better understanding of the emotional content of the doctor-patient and inter-professional relationships, in order to improve the therapeutic potential and effectiveness of these relationships.

Methods We initiated weekly Balint Sessions for junior medical staff working in a tertiary Newborn Intensive Care Unit in Cardiff. The sessions were co-facilitated by a psychiatrist and a neonatal intensive care doctor. Each week, a participant in the group is invited to present 'a case' for 10 minutes, followed by a short period for questions of clarification. Next, the presenter 'pushes back' from the circle, and the other participants respond to what they have heard. Responses take various forms. There may be questions, advice, emotional reactions induced by the story and speculations about what else might be going on. The facilitator gently discourages too much interrogation of the presenter. The presenter is allowed to have her say and respond to what she has heard when she is invited to join in again later.

Results The cases presented have been drawn from a number of themes: for example, challenging clinical situations (such as difficult resuscitations), responding to disability, dying or death, challenging families and difficult interactions with colleagues and peers. $100 \%$ of participants (22 professionals) report a greater sense of well-being having attended the group. The other benefits reported included an improved engagement with reflective practice (both personal and written for e-portfolio), increased team cohesiveness and an increased awareness of their own emotional responses (positive and negative) to clinical practice.

Conclusions Balint groups represent a low-cost, high-benefit intervention for trainee well-being. By mobilising local resources from across disciplines, we are able to support and facilitate a weekly group session that enables the provision of emotional support, reflective practice and a setting in which to explore how professional and personal responses to work are associated, and the consequences one may have for the other.

\section{G378 'THE PAEDIATRIC FAMILY PROJECT': AN EVOLVING PAEDIATRIC MENTORING SYSTEM}

${ }^{1}$ SR Tolan, ${ }^{2}$ S Broughton. 'Paediatrics, Queen's Hospital Romford, Essex, UK; ${ }^{2}$ Paediatrics, Kings College Hospital, London, UK

10.1136/archdischild-2020-rcpch.323
Aims To maximise retention we must ensure that our paediatric trainees feel valued and supported. As part of our retention strategy, in 2014-2015, we initiated The Paediatric Family Project, based upon university buddying systems. It was designed to support new trainees during a recognised challenging period of training.

Methods ST4-ST8 trainees (the 'parents') are recruited through the local paediatric school website for each academic year and matched with a new ST1 trainee (the 'child'). A Typeform survey sent to participants nine months later reviewed experiences of the project. Project improvements are made for the following cohort. As part of an evolving Quality Improvement Project, changes included: matching within the same hospital, providing support for 'parents' throughout the year, online mentor training and social events.

Results The survey was sent to approximately 180 paediatric family members each year. Response rates were 25-29\% each year.

The proportion of paediatric family members meeting has increased steadily each year from $33 \%$ in 2014-2015 to $87 \%$ in 2018-2019. Reasons for not meeting have remained similar and include: lack of interest from other family members and rota incompatibility.

In 2015-2016 we introduced the 'Top ten Tips' guide for all new parents and regular email contact. $86 \%$ of them found it helpful.

In 2016-2017 we introduced free online mentoring training for paediatric parents in response to feedback. Only $13 \%$ of trainees have completed this training.

Conclusion The paediatric family project is an innovative, practical approach to supporting junior trainees. The improved rate of paediatric families meeting, suggests that the location of the family members is vital for the success of the project and that the project is becoming imbedded within the deanery training structure.

The paediatric family project is an ongoing and continually improving venture, which is responsive to the dynamic requirement of paediatric training and evolves with frequent trainee feedback. Feedback from the 2018-2019 cohort has been encouraging: 'My parent was so friendly and helpful, they supported me both pastorally and also with exams, career development and general training questions. I felt more reassured with her support.'

\section{G379 ACHIEVING CLINICAL EXCELLENCE EDUCATIONAL NEWSLETTER}

L Brent, A Soo, S Tran, L Pakkiri. Paediatrics, West Middlesex University Hospital, London, UK

\subsection{6/archdischild-2020-rcpch.324}

Aims Achieving Clinical Excellence (ACE) meetings replaced the traditional morbidity and mortality meetings in a local paediatric department in 2018. This allowed learning to be drawn from positive aspects of care and to develop a Safety$\mathrm{II}^{1}$ approach to patient safety. This project utilised an e-newsletter to disseminate the learning from ACE meetings with supplementary educational content. A secondary goal was to boost staff morale through celebrating excellence in the workplace.

Methods A trainee-led editorial team was established at induction to create content for a celebratory and educational 